\title{
Of Disobedience, Divinations, Monsters and Fumbling: Adopting a Self-Service System
}

\author{
Bob Travica \\ University of Manitoba, Winnipeg, Canada
}

btravica@ms.umanitoba.ca

\begin{abstract}
This article reports on an interpretivist study of the adoption of a self-service-based human resources management system in a Canadian company. The study is based on the Information View of Organization framework. The main finding is that a moderate level of system adoption can be explained in part by several cognitive aspects: comparisons between the new applications and familiar systems, making sense of erratic behavior of user interface, cognitive transformation of HRMS into a symbol with multiple meanings, and perceived support for system use. The contribution of the study is that it enriches current understandings of system adopters.
\end{abstract}

Keywords: System adoption, self-service system, ERP system, cognitive factors, information view of organization

\section{Introduction}

The present study investigated a self-service based human resources management system (HRMS) in a company code-named the Canadian Utilities Company. The software platform for HRMS was mySAPTM — a recent version of Enterprise Resource Planning (ERP) software by SAP corporation. The adoption or acceptance of information systems (ISes) is one of the classical problems in the IS field. It has been studied from the perspective of behavioral drivers that make individual organization members involve ISes in everyday work. For example, the well-known Technology Acceptance Model (Davis, Bagozzi, \& Warshaw, 1989) posits that users' perception of system usefulness and ease of use are antecedents to the user's intention to actually use the system. Essentially, the user is placed in a role of an evaluating agency that determines whether systems are adopted.

Other approaches to system adoption include models that build on the theory of planned behavior (Ajzen, 1991). One driving concept, for example, refers to the subjective norm (the user's perception of other people's opinions about his or her behavior). Another refers to perceived behavioral control (the user's perception of constraints affecting his or her behavior) (e.g., Taylor \& Todd,

Material published as part of this publication, either on-line or in print, is copyrighted by the Informing Science Institute. Permission to make digital or paper copy of part or all of these works for personal or classroom use is granted without fee provided that the copies are not made or distributed for profit or commercial advantage AND that copies 1) bear this notice in full and 2) give the full citation on the first page. It is permissible to abstract these works so long as credit is given. To copy in all other cases or to republish or to post on a server or to redistribute to lists requires specific permission and payment of a fee. Contact Publisher@InformingScience.org to request redistribution permission.
1995). Furthermore, theories of dissemination of innovation have also been deployed in studying systems acceptance. Systems characteristics, for example, can play a decisive role (e.g., Karahanna, Straub, \& Chervany, 1999). These approaches have made significant contributions to understanding the psychology and action of the system adopter. Still, it can be argued that a 
sharpening of analytical lenses is warranted.

IS research needs to focus more precisely on the key concepts that distinguish its subject of adoption from all others. As the perspective of Information View of Organization (IVO) suggests (Travica, 2003, 2004, 2005a, 2005b, and forthcoming book), one way to do this is by examining closely information and information technology (IT). The models of adoption cited above are applicable to any context. One can adopt an IS as well as a new car; one can plan behavior related to system adoption as well as to the way one asks for a raise in pay; and the dissemination of an innovation could relate to any new thing under an organization's roof, including a multi-million ERP system. In each of these adoption instances, similar psychological factors are at play. Although this assumption is tenable on the ground of general systems theory and helps in understanding certain aspects of user behavior, the question remains: how is adoption of IS different from other adoptions? How can IS research distinguish its subject of research from approaches taken in so-called "reference disciplines" (Baskerville \& Myers, 2002; Steinbach \& Knight, 2006) beyond linguistic changes in data collection instruments, which merely designate some systems to be the subject of users' adoptive deliberations? The study reported in this article is an attempt in this direction. It draws on the cognitive part of the IVO framework, which brings to the fore characteristics of individual organization members (perception, thinking, feeling, learning, and knowledge), problems of meaning (one form of information in the IVO framework), and symbols - all centered on particulars of a specific IS.

Another motive behind this study is to fill a void in research on self-service systems. These systems require end-users to directly manipulate a system without the help of intermediaries. Many people routinely resort to self-service when using ATM machines or shopping on the Web. In the organizational context, elimination of intermediaries means that data entry, querying, and other system tasks are the duties of casual users rather than of trained "power or expert users" serving as intermediaries. This increment in work of casual users may be perceived differentlysometimes as desirable (e.g., students who can directly access their records), sometimes as a change with ambiguous net benefits (e.g., doctors who must do the job previously done by nurses). In principle, self-service applications could signal a major change in work processes and organizational cultures, since all organization members can become systems users. In spite of this increasing importance of self-service systems, however, the relevant literature is still meager (e.g., Lapointe \& Rivard, 2005; Larsen \& Myers, 1999; Stein, Hawking, \& Wyld, 2005). Finally, the last purpose of the study is to advance testing of the IVO framework.

\section{Literature Review}

The literature on self-service systems has only recently begun to develop. Stein and colleagues (2005) identified a success story of a self-service-based application for pay, leave, and benefit packages in an Australian telecommunications firm. The authors reported a 40\% reduction in administrative staffing, $80 \%$ reduction in management $\mathrm{HR}$ duties, and $50 \%$ reduction of transaction costs. In contrast, Larsen \& Myers (1999) discovered serious difficulties in the adoption of a SAP accounting module in a financial firm in New Zealand, where the accounts payable process was based on self-service. The difficulties included a failure to re-engineer business processes before implementing the system, a lack of reports, and dissatisfied users. Although the number of accountants was reduced by $68 \%$, the knowledge of the laid-off employees was lost, resulting in low skill and morale among those who remained. Finally, Lapointe and Rivard (2005) found that enterprise systems may fail if the political positions of key user groups are threatened. Doctors who were to enter prescriptions into new electronic medical record systems sabotaged the systems in three of four hospitals in Quebec. The doctors severely criticized the systems for imposing extra, non-professional work on them. They eventually succeeded in retaining their preferred manual method of dictating prescriptions to nurses, making the adoption unsuccessful. 
The broader literature on adoption of ERP systems also provides valuable insights. For example, Sarker and Lee (2000) found that adoption of an ERP system was associated with changes in the organization's old "dysfunctional culture" that was marked by a "sea of paperwork," lack of communication between divisions, and scheduling errors. In contrast, Krumbholz and Maiden (2001) found that implementation of SAP R/3 in a pharmaceutical firm did not fulfill the promises of achieving integrated data because the system was not configured uniformly across organizational units. Even more dramatic events surrounding implementation of an ERP system were discovered by Bulkeley (1996). The author found that a combination of unprecedented external difficulties and implementation mistakes (poor testing, insufficient user training, and a rushed rollout) was responsible for the disastrous effects of implementing in a big-bang strategy SAP modules at Fox-Meyer Drug.

Also relevant for my study is the Markus and Tanis' (2000) process model of the cycle firms go through in implementing ERP systems. The model contains four phases, beginning with the planning and ending with the routine use of a system. In between comes a "shakedown phase" that corresponds to system adoption. In this phase, a system and users strive to achieve routine use or else may end up with a system shutdown. Problems may occur during a shakedown, such as the maintenance of old processes, poor software ease of use, stalled user skills, and low usage of system. The main methods of overcoming adoption challenges include a well-configured and integrated system, redesigned business processes, trained users, resources to address problems, and action to fix problems.

\section{Theoretical Framework}

This study is conceptually based on IVO. This choice resulted from the research goal to advance testing of this new conceptual and analytical framework. IVO draws on the IS, organization and cognitive theory, and places information and IT at the nexus of organization. Information is conceptualized as an informing agent that takes the form of data, meaning, knowledge, and wisdom. IVO has been described in more detail elsewhere (Travica, 2003, 2004, 2005a, 2005b). It will suffice here to mention that IVO approaches individual organization members from a cognitive perspective. It views an individual as agency that actively creates, evaluates, adopts, and uses IT and information in its various forms. Information forms (meaning, knowledge, and wisdom) reside in the user's mind. These can be represented in ISes, but they are not located there. Only the simplest form of information - data — can be stored in systems. Therefore, focusing on cognition is paramount to understanding information that is the raison d' être of ISes.

The cognitive focus is also important for studying IT - another key phenomenon in IS research. Although IT is a physical object, it also exists through representations in the user's mind (e.g., as a subjective concept that abstracts just some characteristics of a system or that attributes new characteristics to a system). The term "homo informaticus" is used in IVO in order to signify the cognitive approach to individual organization members. IVO assumes that homo informaticus actively interacts with cognized characteristics of an IS in the process of adopting it in a particular organizational context.

A model of homo informaticus is depicted in Figure 1 (Travica, forthcoming). The model draws on cognitive psychology, good summaries of which can be found in Bara (1995) and Eysenck and Keane (1995). Therefore, homo informaticus refers to a complex that consists of several cognitive processes and cognitive states - perceiving process (percept is the corresponding state), learning (meaning, knowledge), memorizing (memory, which can be in several states), feeling (emotion), and thinking (thought). The concepts relevant for this article will be defined at appropriate place in the discussion that follows. 


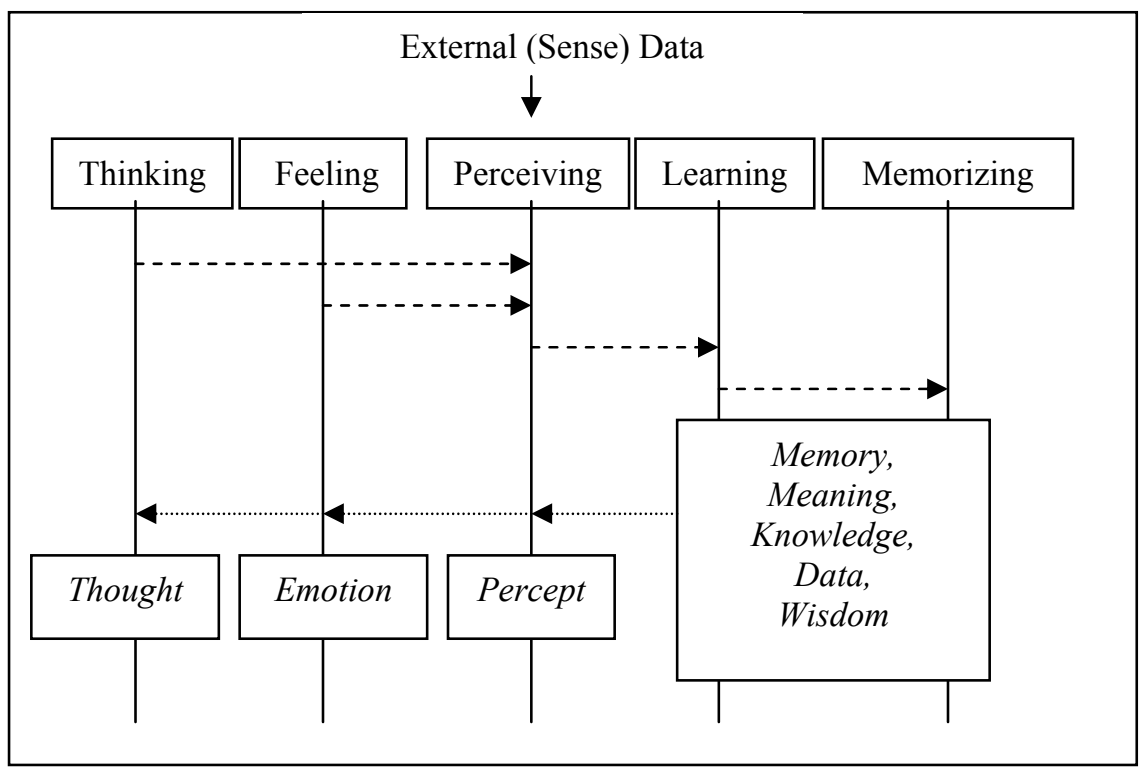

Figure 1: Cognitive makeup of homo informaticus

\section{Study Field and Methods}

The field investigation was situated in the Canadian Utilities Company, an established, government-owned company employing about 5,000 employees. It had a monopoly in a regional domestic market, while competing in the US market. The employees were professionals, managers, clerks, and workers in various trades. The organizational structure was bureaucratic, and the IS and HR functions were centralized. Implemented recently, the centralization of the HR function had been driven by a strategic goal of rationalizing administration. This included a reduction of the clerk/employee ratio. HRMS, the system under investigation, had been touted as an important vehicle for achieving this goal.

HRMS consisted of two modules. One was for all employees to enter and query their time, expenses, travel, and professional development. This module would be labeled SSE ("self-service of employees"). The other module allowed managers to make online approvals of employees' reports, claims, and requests. It would be labeled SSM ("self-service of managers"). SSE and SSM were functionally connected, since the output of the former provided the input for the latter. Technically, SSE was just a new user interface that was layered on top of a core R/3 SAP system. This user interface was implemented in the SAP portal. The older application with nearly the same functionality used Web forms to access the R/3 system. It had been developed exclusively for clerks' use, and was successfully adopted a few years earlier.

With SSM, 700 supervisors and managers were expected to look up data online on their own, create reports, and make approvals by entering checkmarks in boxes on screens. Since access to HRMS was protected by a portal password, clerks were normally prevented from doing what they did previously for superiors. However, 150 clerks were allowed to access SSM with limited privileges. This allowed them to help managers in certain tasks, and to assist workers who had limited or no access to HRMS. Clerks also continued to administer time and expense data on behalf of field workers by using the older Web forms-based user interface to the R/3 system.

The research design deployed in the study was characterized by a case approach (Yin, 2003), interpretivist epistemology, triangulated data collection, and a coupling of data collection with coding. The last method was similar to the grounded theory approach (Charmaz, 2006; Glasser \& Strauss, 1967). The data were collected over six months in 2005-2006. The main collection tech- 
nique was interviewing. I interviewed a total of 33 persons, including 4 focus groups (11 persons in total), which yielded 22 hours of interviews. Data collection and sampling started from an internal informant, and unfolded through snowballing and intentional sampling. The sample exhibited variability in terms of professional background (humans resources, information systems, engineering), hierarchy (executive, mid-level and supervisory management), tenure (from 5-35 of working for the company), and geographical location (the central location with the headquarters and main business, information systems and engineering operations as well as three other loci where production operations are performed). I tape recorded the interviews with the consent of the respondents, and took notes during each interview. With the exception of one focus group held via videoconferencing, the interviews were face-to-face. The interview design varied from open-ended to semi-structured, with the exception of a structured interview with the CEO.

Coding was conducted during data collection, which provided for gradually developing data analysis categories. Coding was applied to interview notes and transcripts. It was complemented by comparison of the codes, writing of memos on code definitions, diagramming relationships between codes, and formulating emerging research questions. This blending of data collection and analysis has been used in different venues of qualitative research, such as ethnography (Orlikowski, 1992; Suchman, 1987; Tedlock, 2000) and grounded theory (Charmaz, 2006; Glasser \& Strauss, 1967). Note that the entire coding and data analytic framework is larger than it is reported here. This article reports only on the homo informaticus aspects of the system adoption process, whereas the larger set of findings includes other IVO dimensions as well. Following a path similar to grounded theory methods, the coding was kept at a basic level for long, by using common sense vocabulary and resisting to aggregate categories into broader ones. Assigning aggregate categories (e.g., the systems' comparisons and the symbolic representations of HRMS) to IVO dimensions was performed at the very end of data analysis. The homo informaticus dimensions were differentiated, for example, from dimensions of infopolitics and infoculture based on their definitional domains (see the previous section).

\section{Shakedown Phase: Whole Lotta Shaking}

The study determined that HRMS was moderately adopted after about a year in its "shakedown phase" (Markus \& Tanis, 2000). The findings reveal an uneven acceptance across applications, user groups, and IS aspects. This evidence is consistent with findings of several user surveys conducted in the Canadian Utility Company, including one during the study. From the IVO perspective, evaluative statements of stakeholders - users, users-to-be, and system championsrepresented crucial evidence on HRMS adoption. A sample of these statements is presented in Table 1. The categorization shown in the left column indicates different ways of thinking about HRMS - as a whole application, as technology built into the system, and as information supported by the system. "Information" refers to the data maintained or processed by the system and the meaning that these data elicit when a user engages the system in a task.

The SSE module enjoyed higher acceptance than did the SSM module. Different groups accepted HRMS to different degrees. The staffs in the centralized HR function were an early adopter. Division clerks authorized to work with SSM also endorsed the system, albeit not as uniformly as the HR staff. Consider this comment of a seasoned clerk: "Honestly, I don't go into [SSM] now. I don't find it that great of an advantage to myself." Instead, the clerk used the older application of $\mathrm{R} / 3$ mentioned above.

Divisional management (managers and supervisors), which comprised 80\% of the user body, seriously challenged SSM. A lack of willingness to accept it was coupled with instances of apparent resistance. The frequent target of managers' criticism was the system's usability. Some characterized the system as "unintuitive," "clunky," "illogical," and "convoluted." The IS experts admitted 
that HRMS had presented some new technical challenges. As one put it: "Those [time and expense applications] are very complicated processes for us, and [with] the software that we use it's difficult to make it user-friendly."

Table 1: Adoption indicators

\begin{tabular}{|c|c|}
\hline Category & Instance \\
\hline $\begin{array}{l}\text { System Mod- } \\
\text { ule } \\
\text { (Application) }\end{array}$ & $\begin{array}{l}\text { - "I work all over the Province. [...] Wherever I hook into our portal, anyplace I can } \\
\text { get my e-mail, I can get [SSM]. And I can do my approvals basically on anyone's } \\
\text { computer." (supervisor) } \\
\text { - "Now with [SSE] you go right into expenses, and one big advantage that I see [...] if } \\
\text { you forget to keep yourself a copy, all the information is here with your past expenses. } \\
\text { And it is automatically deposited in your bank through the system." (clerk) }\end{array}$ \\
\hline $\begin{array}{l}\text { IT, } \\
\text { Usability }\end{array}$ & $\begin{array}{l}\text { - "Anything that you need this much information on [one inch-thick user manual or } \\
\text { SSM] is not user friendly." (manager) } \\
\text { "Our field staff [...] get so frustrated with it [SSE] that a lot of times we end up doing } \\
\text { their expenses for them." (clerk) } \\
\text { - "If I have to figure it out again and have to dance around this thing [HRMS], and it } \\
\text { isn't self explanatory, that frustration is what causes me grief." (supervisor) } \\
\text { - "You have to use it [SSM] all the time to become proficient with it." (manager) } \\
\text { - "I have said all along ever since SAP came along here: if it were easier to use there } \\
\text { wouldn't be half of the push back." (IS executive) }\end{array}$ \\
\hline Information & $\begin{array}{l}\text { - "[SSM] is a real handy tool for information on my staff." (manager) } \\
\text { - Employee profiles are more complete and very useful. (managers, supervisors) } \\
\text { - "It is really nice to see all your training [in SSE]." (clerk) } \\
\text { - "Real time data can be used for figuring out sick days in a department, job candidate } \\
\text { lists, and this can enable appropriate action (e.g., contact people to stir up interest in } \\
\text { job openings)." (HR professional) } \\
\text { - "The majority of users were very appreciative of the new information that they had } \\
\text { and that they could put their hands on." (HR manager) }\end{array}$ \\
\hline
\end{tabular}

Management went beyond criticizing IT. The process change coinciding with system adoption actually aggravated the adoption process. One manager phrased it clearly: "There have been two changes that have come simultaneously - the process change and the tool. So the tool is maybe getting blamed for part of the process." Why did management oppose new processes? The following frank comment was telling: "I personally feel, with the introduction to the application [SSM], that it has created more work for managers." Many respondents also shared a conviction that the additional work "is not value-adding," and, thus, it should be performed by clerks.

In contrast to IT built into HRSM, information supported by HRMS appeared to be more welcome (see Table 1). But there was a tension between the provision of better information on one hand, and the shortcomings in technology on the other; the former came at a significant cost in terms of the learning curve and the effort required. Consequently, IT reduced the benefits of potentially better information, negatively affecting the adoption of HRMS. 


\section{Disobedient Expensive System: Workings of Schemata}

The main message drawn from the system adoption situation in the Canadian Utilities Company is that the adoption process has a salient cognitive component that is responsible for the moderate breadth and depth of adoption. In coping with HRMS, the users had to go through a great deal of learning that reached beyond how-to-do knowledge. As the study illustrated, this learning can be described in terms of developing declarative knowledge via several paths. One path is instantiated in comparing the novel self-service with familiar systems. Another involves making sense of the system's erratic behavior. The third path of learning about the system is a cognitive transformation of HRMS into a symbol with multiple meanings. These learning aspects are complemented by the users' perception of support received, which is intimately linked with the users' motivation. These four cognitive dimensions play a role in the moderate level of HRMS adoption. Each will be discussed in turn.

Comparing HRMS with previously experienced systems is a method of learning that extensively engages mind of users. Previous knowledge, perception, as well as thinking and feeling processes seem to be at work. In cognitive psychology, previous knowledge has been studied in the theory of schemata. A schema (pl. schemata) refers to a well-integrated chunk of knowledge about the world, events, people, and actions (Eysenck \& Keane, 1995; Schank and Abelson, 1997). This knowledge is called "declarative" and is represented in terms of concepts, propositions, and frames. For example, the concept of computer may include an idea of its purpose and a mental image of a PC monitor and keyboard. A proposition may be the statement: "A computer consists of software and hardware." Frame refers to even a more complex form of knowledge that entails properties of objects and locations (e.g., an analytical understanding of hardware that constitutes a PC). The development of new concepts, propositions, and frames is a learning process that progresses through processes of perception, thinking, and feeling - each relying on existing schemata. (This impact of schemata is sometimes called top-down processing). Thinking processes, based on some sort of logic, complement the development of schemata. These include comparisons, analysis, synthesis, induction, and deduction. All of these processes and schemata are important aspects of the homo informaticus that can play a role in systems adoption.

It follows from the premises above that the schemata, in conjunction with thinking processes, work both as enablers of, and filters for learning about a new IS. The adopters of HRMS showed a salient tendency to compare the new system with other systems they knew. As indicated in Table 2, comparisons were made with a paper-based time carding system; previous computer-based systems for time administration; an alternative system, still in use, that had a different user interface to R/3 (see above); Internet; Google; Microsoft Excel; and Microsoft Word. The systems comparisons resulted in propositions about and frames of HRMS' user interface and functionality. As the citations in Table 2 indicate, the systems used in the past faired better than HRMS. The same goes for free Internet services. Even Microsoft applications software, which can hardly be considered an epitome of usability, fared better than HRMS. A few respondents compared the ease of manipulating columns in Microsoft Excel files with the unwieldy, wide tables of HRMS, which forced users to frequently scroll screens horizontally. All in all, HRMS was labeled an uncooperative, disobedient system that cost a lot of money, and this contradiction was magnified by comparisons with older systems and Internet services that faired better on both counts.

Interestingly enough, an upgrade of user interface was implemented, which allowed for customizing the layout of tables. Both this and a fix for "screen flashing" (next section) came after a significant pressure from the HR department and users on the IS function. 
Table 2: Schema-based system comparisons

\begin{tabular}{|l|l|}
\hline Frame of Reference & \multicolumn{1}{c|}{ Instances } \\
\begin{tabular}{|l} 
Paper Time Carding \\
System
\end{tabular} & $\begin{array}{l}\text { "Comparing to the old time carding system that we had, not everyone did } \\
\text { their time cards the same way. So, you could go to different towns or cit- } \\
\text { ies and [...] you wouldn't be able to approve your time cards there." (su- } \\
\text { pervisor) }\end{array}$ \\
\hline $\begin{array}{l}\text { The Historically First } \\
\text { Electronic HR Sys- } \\
\text { tem }\end{array}$ & $\begin{array}{l}\text { "PayPers was a payroll system that was very difficult to work with. [...] } \\
\text { The reporting was terrible." (manager) }\end{array}$ \\
\hline $\begin{array}{l}\text { The Historically Sec- } \\
\text { ond Electronic HR } \\
\text { System }\end{array}$ & $\begin{array}{l}\text { "It was the easiest system in the world to work with regarding time card- } \\
\text { ing, overtime, meals, etc." (supervisor) }\end{array}$ \\
\hline $\begin{array}{l}\text { Alternative } \\
\text { R/3-Based System }\end{array}$ & $\begin{array}{l}\text { "There may be a day I don't use [HRMS] because I do time entry directly } \\
\text { into the SAP system. [...] That is the most comfortable way for me to go } \\
\text { in. Sometimes if a client or supervisor has expenses, he still fills out the } \\
\text { form instead of going in here [SSE] and doing it. So, I fill it out." (clerk) }\end{array}$ \\
\hline Internet & $\begin{array}{l}\text { "I can do almost anything I want in that silly system [Internet]. I don't } \\
\text { even pay for it; it is just there. And here you have developed this system } \\
\text { for our corporation, and it doesn't do what I want it to do." (HR execu- } \\
\text { tive) }\end{array}$ \\
\hline
\end{tabular}

\section{Divining Mysterious "Screen Flashing"}

The system adopters in this study also learned about HRMS by coping with and making sense of erratic system behavior manifested through the user interface. This discovery came in several steps. I learned in early interviews and witnessed myself that HRMS screens would flicker whenever a user would click the mouse to enter a check mark in a designated checkbox. Users called this "screen flashing." Both the system champions and SAP experts confirmed its existence and concurred that this was "a problem." An HR executive characterized the screen flashing as a "major annoyance" for many people. Even the manager in charge of SAP, who had power to rectify the problem, did not spare criticism: "Users see that ["screen flashing"] and they know it's not attractive. And they know that it's a stupid thing, really." Another SAP expert, who had a long tenure as application tester and instructor, identified this error with the company's "habit of not finishing off applications." Instead of refining applications to optimize their usability, the development process would end prematurely and developers would move on to another application. I used these leads to investigate systematically the users' experience with this erratic system behavior.

The investigation indicated a lack of homogeneity in users' perceptions. Some confirmed that the screen "flashed" on them and framed this as inconvenience, annoyance, or a symptom of an illdesigned application. Others claimed that they had not experienced the "screen flashing." Some of the latter respondents said that they learned about it from colleagues. Nearly all of the naysayers were managers. A representative statement from them was: "I noticed [a mention of "screen flashing"] in the [user] survey and I remember hearing it in the conversations. But I haven't had problems that way." (See also Table 3.) Still, a professional who closely monitored the system adoption asserted that users could have experienced screen flashing even though "they did not know it." This is consistent with the statements of the SAP experts cited above. Managers could have overlooked "screen flashing" because they had a limited exposure to HRMS. 
Table 3: Grasping erratic behavior of HRMS

\begin{tabular}{|l|l|}
\multicolumn{1}{|c|}{ Category } & \multicolumn{1}{c|}{ Instances } \\
\begin{tabular}{|l|l|} 
Screen Flashing \\
Symbolism
\end{tabular} & $\begin{array}{l}\text { - "A really stupid thing." (SAP manager) } \\
- \text { "A major annoyance." (HR executive) } \\
- \text { "It [screen flashing] is not a big deal. You can enter it [data] and then it } \\
\text { scrolls through. You approve it and carry on. For the five seconds that it } \\
\text { takes, it is not a big problem for me." (clerk) } \\
\text { - "As far as this flashing, I didn't have a clue what they were talking } \\
\text { about because we had never seen it." (manager) }\end{array}$ \\
\hline Grapevine Influences & $\begin{array}{l}\text { - "I have heard many times that the way the information is set up on the } \\
\text { screen is very difficult to follow." (clerk) } \\
\text { - "I haven't [experienced screen flashing] but I have heard all kinds of } \\
\text { people talk about it." (manager) }\end{array}$ \\
\hline
\end{tabular}

The SAP unit's head explained that the screen flashing was caused by a screen's refreshing, which, in turn, was caused by conversion of the output from the R/3 system into output on the SAP portal. The problem could have been fixed, explained this manager, but only by customizing the system, which would have amounted to changing the source code. Throughout the interview, this person adamantly rejected the possibility of customizing the system, since that would have meant giving up the support of the vendor. Instead, the manager ascertained that waiting for the vendor to solve the problem with new releases of software was a better solution. Surprisingly, the SAP staff fixed "screen flashing" during the execution of my study even though new SAP technology was not yet made available.

From the IVO perspective, the "screen flashing" episode reveals a rich cognitive and social context characterizing the adoption of HRMS. First, users have differing perceptions of the system behavior. What constitutes a tangible fact for one group is non-existent for another group. IVO accounts for a complexity in the cognitive makeup of homo informaticus, which implies variation in perception. Second, the shared experience of the instability of screens can be explained by invoking the concept of affordances (Gibson, 1979). Affordance refers to the rich visual data that objects provide or "afford." These data are important for shaping the meaning in the observer's mind. Their impact is sometimes called "bottom-up processing." Eysenck and Keane (1995) stipulated that Gibson's theorizing on bottom-up processing needs to be coupled with the concept of top-down processing (see above). The former helps to recognize an object, while the latter helps to determine what an object is in terms of its purpose, behavior, etc. Thus, "seeing" is different from "seeing-as" (Eysenck \& Keane, 1995). The latter process has to do with the attribution of meaning to percepts, in which a decisive role belongs to previous knowledge. For example, any lost fisherman can see the North Star on the clear night sky, but not every fisherman may know that it is the North Star. Therefore, if affordances shape the elemental meaning of objects, schemata shape a higher level of meaning. In the case of "screen flashing," schemata entail an understanding why screens behave that way. When I asked respondents for an explanation, they provided various interpretations. One diagnosed the phenomenon as "a bug that can be fixed." Another thought that it was "an unfixable feature of the current SAP technology." Other explanations pointed to peculiarities of the portal product used, the links between the portal and the R/3 system, or problems in data transfers between the servers engaged. 
This divining of the puzzling and often annoying behavior of HRMS demonstrates that organization members engaged in an adoption process create differing meanings of the same affordances. This cognitive dynamic, therefore, charts one path of making sense of the system.

\section{A Monster Eating Value-Adding Work: Symbols and Power}

One way HRSM users learned about the system was mediated by a cognitive process of transforming HRMS into a symbol with multiple meanings. A symbol stands for something other than itself; it triggers a meaning beyond itself. Put another way, a symbol has connotative rather than denotative meanings. Symbols can take different forms, including objects (e.g., IT symbolizes efficiency), concepts (e.g., efficiency attributed to IT further symbolizes progress), and acts (e.g., managers' information-seeking behavior may symbolize a rational approach to decision making irrespective of how decisions are actually made (Feldman \& March, 1981)). Czarniawska-Joerges (1992) advanced the theme of organizational symbolism into a distinct area of research. She argued that symbols stand ambiguously for a multiplicity of things, evoke emotions, and impel to action (p. 141). She also pointed out a link between organizational symbols and power; individuals and groups can manipulate symbols for the purpose of gaining/maintaining power. These premises are important for understanding more deeply the cognitive aspects of the HRMS adoption process.

In my study, divisional management proved to be an outspoken critic of HRMS. As cited above, many supervisors and managers felt that the SSM module had imposed more work on managers. In their mind, the system became a symbol with multiple meanings. It connoted "non valueadding work," and "administrative tasks that are offloaded on them." SSM also symbolized an alien thing, "a huge monster" or "a new animal" that caused users "to dance around it" and "to run around it like a yo-yo." SSM also stood for a threat (Commented one supervisor, "I think we'd all say that we all feel that we're starting to get crippled by the computer."). Overall, therefore, HRMS symbolized an alien force that disturbed the life of divisional management. The shortcomings in HRMS' usability intensified the repulsiveness of the symbolism.

The case of the Canadian Utilities Company is congruent with insights from the Lapointe and Rivard (2005) study of electronic medical record systems in three Canadian hospitals. Once the new systems were in place, physicians were obliged to enter prescriptions into the system instead of dictating these verbally to the nurses. The physicians resisted the new process and argued that the system pushed them toward a lower productivity and quality of service. The new systems, therefore, symbolized an alien force threatening professional objectives much like HRMS did in my study.

In the course of systematically resisting the new system and the prescription process, the physicians in Lapointe and Rivard's (2005) study transformed the undesired systems into repulsive symbols. The eventual consequence of this battle of symbols was the undermining of the electronic medical record systems. A beneficial consequence for the physicians was that they preserved their old political position vis a vis nurses. As noted earlier, organizational symbols can be intimately connected with organizational power and politics. By analogy, the disgusting symbols attributed to HRMS at the Canadian Utilities company could be understood in terms of a manipulation of symbols by divisional managers. Their ultimate goal was to protect their turfs vis a vis clerks and the human resources department. The epilogue to this story is yet to be written. 


\section{Befriend a Techy or Fumble: Perceived User Support}

Users ' perception of the support they received in the adoption of HRMS turned out to be yet another cognitive factor involved in the process. The evidence reveals certain feelings and thoughts that the users shared. I coded these in three categories: perceived training, perceived helps, and perceived system maintenance.

Perceived training refers to the user's assessments of formal instruction in the use of the system. Training for both modules of HRMS was arranged and my respondents received it. But the users pointed to certain shortcomings. One explained: "We all went through the training. [...] But there have been lots of changes since we first rolled out." Some changes in the user interface came unexpectedly and threw users off balance (see Table 4). Another user criticized the length of a training session and its detachment from real needs (Table 4).

Table 4: Users' perception of support

\begin{tabular}{|c|c|}
\hline Category & Instances \\
\hline $\begin{array}{l}\text { Perceived } \\
\text { Training }\end{array}$ & $\begin{array}{l}\text { - "They send you to an all day session and they cover everything that it [the sys- } \\
\text { tem] can do. But you know what you are not interested in. I can picture in } 10 \\
\text { min of what you have to do. Let's focus exactly on what you're going to be do- } \\
\text { ing." (clerk) } \\
\text { - "We all went through the training. [...] But there have been lots of changes } \\
\text { since we first rolled out." (supervisor) } \\
\text { - "There have been a few changes to the look and the feel of the application of } \\
\text { the system as a result of the new portal. One of my customers was calling and } \\
\text { saying, 'I don't understand how it works, where do I go, and I can't find it."” } \\
\text { (HR professional) }\end{array}$ \\
\hline $\begin{array}{l}\text { Percei } \\
\text { Helps }\end{array}$ & $\begin{array}{l}\text { - "And so they give you another upgraded version, some that you have to go and } \\
\text { take a course on and some that you don't. You kind of fumble your way through } \\
\text { it." (supervisor) } \\
\text { - "Unless you go looking, you don't know what you have... When I figured out } \\
\text { how to go in and get the information, it was all there, but I didn't have a clue it } \\
\text { was there." (manager) } \\
\text {-“I just pick up the phone because I still know who they [potentially helpful IS } \\
\text { professionals] are." (clerk) }\end{array}$ \\
\hline $\begin{array}{l}\text { Perceived } \\
\text { Maintenance }\end{array}$ & $\begin{array}{l}\text { - "They [a process group] are supposed to hear about all the glitches but they } \\
\text { have not met in some time." (technologist) } \\
\text { - "It [support for HR applications] is probably less than adequate. We need to } \\
\text { make some changes that are really important in terms of our customer satisfac- } \\
\text { tion. We are fighting against this priority and resource issue." (HR executive) } \\
\text { - "We have so much change, and we are not finishing change off before we go } \\
\text { to the next change. And these things don't ever seem to get finished off, and } \\
\text { they go farther and farther and farther. And those little problems affect the } \\
\text { moral of the people." (SAP tester and instructor) }\end{array}$ \\
\hline
\end{tabular}


What could the HRMS users do when in trouble? They could use some of the formal or informal methods of support to solve their problems. I coded these with the term "Perceived helps." One of these was the help desk staffed by both the technical and the HR staff. There were some indications that the help desk was busy and helpful. But I also found that some respondents felt as if they were left on their own and doomed to "fumble" through the system (Table 4). Lucky ones had an emergency telephone line connecting them to SAP experts with whom they were already acquainted (Table 4). This inequality in the perceived helps indicates a lack of attention to an important detail in the systems adoption process. Official statistics on the number of incidents the help desk handles hide these negative perceptions. However, awareness of them matters a great deal in motivating an organization to adopt the system.

Perceived maintenance was yet another means of support for HRMS adopters. In the period of the study, the SAP developers fielded more than a thousand requests for system changes. These were collected in various ways, including user survey responses, calls to the help desk, and maintenance requests of the system owners in the HR department. However, a dedicated work group that was supposed to be the key institutional interface between developers and users did not function in the shakedown phase (Table 4). Moreover, prioritizing of maintenance requests was a point of contention. While the SAP managers claimed that prioritizing had been done according to prescribed procedures, their HR counterparts ascertained that prioritizing was up to the SAP group. Said an HR executive:

As far as I know, it is the SAP group that decides. Well, they are not the customer and they don't necessarily understand the corporate priorities. They don't come and talk to us and try to [gain] understanding from us... Our portal system is being changed; somebody had to make that decision that was taking priority over the flashing screen, for example.

Indeed, when maintenance involving deeper interventions was concerned, the SAP manager agreed with the above identification of power allocation:

So, we made a decision, although we knew it wasn't attractive, realizing that they [the SAP vendor] were going to fix it ["screen flashing"] in the future. [...] So, there are some things like that we know about, that we know we want to fix, but we just sort of have to wait.

Potential diminishing effects of maintenance shortcomings on the motivation of HRMS adopters were crisply diagnosed by the SAP tester and instructor: "These things don't ever seem to get finished off, and they go farther and farther and farther" (see Table 4). While he was able to sort out rationally the possible causes of insufficient user support via system maintenance, a divisional manager concurred with the diagnosis. "Sometimes I think people in the project are so close to it and they want to see it go ahead [so badly] that, even though they hear concerns, they underestimate their impact." This manager had a lengthy and detailed list of critical remarks prepared for the interview. It appears that the manager's motive to help improve the system conflicted with a feeling of being powerless to influence the maintenance process.

\section{Conclusion}

The study HRMS adoption in the Canadian Utilities Company has two noteworthy limitations: it has captured a historically limited, shorter piece of the adoption process, and it used the singlecoder method. Nevertheless, the case sheds the light on several aspects of individual cognition that develop when a self-service-based system is being adopted. In particular, the study suggests that cognitive factors can help to explain why the most critical user group-divisional management - keeps rejecting the SSM module of HRMS, running counter to the two other user groups - the HR staff and divisional clerks. Cognitive factors explain how the reluctant adopters 
learn about the system and become motivated to slow down the adoption. These factors include: comparisons between the novel self-service applications and familiar systems; attempts to make sense of erratic behavior of the system's user interface; cognitive transformation of HRMS into a symbol with multiple meanings; and perceived support for system use.

Previous experience with various ISes influences the way in which users evaluate HRMS. Freely available Internet resources thus feature as a benchmark of smartness and capability; these, in turn, render costly HR applications ineffective and expensive. These applications have proven to be inferior, even in comparison with commercial application software that is not often considered a benchmark of usability. These insights demonstrate how users' schemata can block system adoption. A practical message also emerge from the study: System champions must pay attention to users' previous knowledge. Rather than succumbing to the blocking effects of the schemata, system champions must turn the schemata into a basis for both the users' learning and corrective systems maintenance. The first steps in achieving this are to acknowledge the schemata and to try to understand it.

Part of coping with the adoption of HRMS entails making sense of erratic behavior of HRMS' user interface. I found that the "screen flashing" affordances left a mark in the minds of some of the users but not all, which indicated an interesting variation in users' perception or meaning creation. Where such affordances did come into play, individual schemata precipitated differing "divinations" of their causes. To influence a higher level of adoption, therefore, HRMS champions must allocate resources to take action to fix such problems (Markus \& Tanis, 2000). Indeed, the Canadian Utilities Company proved the principle: the champions in the HR function identified the problem and pushed for solving it, eventually removing the annoying "screen flashing." However, the champions on the IT side demonstrated a lack of sensitivity toward other difficulties that users experienced, refusing to take corrective action even though they were fully aware of the problems. The implication for practitioners is clear: The IS staff must internalize the axiom that the user interface is the system for users. This is particularly important in the case of selfservice systems that put an extraordinary burden on casual users.

As symbol makers, HRMS users tend to invoke a perceived reality in which the system poses as "a huge monster" or "a new animal" that users have to "dance and run around like a yo-yo." The system becomes a demon that devours management's time for value-adding work. Such a repulsive symbolism undoubtedly blocks adoption of the system, especially the SSM module. Repulsive symbols serve as the breeding ground for resistance toward the system. A practical implication is that promoters of a self-service system should not neglect the symbolism developed during the system adoption process. To understand the seriousness with which HRMS symbolizes a visible disturbance in the life of divisional management, one needs to move beyond standard surveys of user satisfaction. At minimum, an open-ended question can be added, which asks users to reflect freely on how they feel about the system.

Perceptions of training, helps received, and system maintenance can also have effects on the adoption of HRMS. Evidence indicates that the help desk was busy and so were developers who worked on a long list of requests for systems modifications. Training for using both modules of HRMS was provided. But statistics on user support veiled some unfavorable perceptions that had developed among the users. Training was perceived as unnecessarily broad and unfocused on specific needs of user groups. Also, changes resulting from extensive corrective maintenance of the system partially obliterated the benefits of the training. Although voluminous, maintenance was still perceived as insufficient. In addition, helps were not administered evenly among users, and some felt they were left to find their own way out of technical difficulties.

The four cognitive aspects provided a partial explanation of the rejection or low acceptance of HRMS among the key user group (managers and supervisors). The study also discovered factors 
of political and cultural character (not discussed here) that worked in concert with the cognitive ones. Admittedly, the study captured only the system's shakedown phase, which prevents from making final conclusions about the fate of HRMS adoption in general. Nevertheless, insights into dynamics of system comparisons, user schemata, system affordances, system symbolism, and users' perceptions of support do illuminate cognitive aspects of the self-service systems adoption process. Previously unstudied, these aspects contribute to theorizing on systems adoption.

\section{References}

Ajzen, I. (1991). The theory of planned behavior. Organizational behavior and human decision processes, $50(2), 179-211$.

Bara, B. (1995). Cognitive science: A developmental approach to the simulation of the mind. Hove, UK: Lawrence Erlbaum.

Baskerville, R., \& Myers, M. (2002). Information systems as a reference discipline. MIS Quarterly, 26(1), $1-14$.

Bulkeley, W. M. (1996). When things go wrong. The Wall Street Journal, Nov. 18, 1996, R25.

Charmaz, K. (2006). Constructing grounded theory. London: SAGE.

Czarniawska-Joerges, B. (1992). Exploring complex organizations: A cultural perspective. Newbury Park, CA: SAGE.

Davis, F., Bagozzi, R., \& Warshaw, P. (1989). User acceptance of computer technology: A comparison of two theoretical models. Management Science, 35(8), 982-1003.

Eysenck, M. \& Keane, M. (1995). Cognitive psychology: A student handbook. Hove, UK: Lawrence Erlbaum Associates.

Feldman, M. \& March. J. (1981). Information in organizations as signal and symbol. Administrative Science Quarterly, 26(2), 171-186.

Gibson, J. (1979). The ecological approach to visual perception. Boston: Houghton Mifflin.

Glasser, B., \& Strauss, A. (1967). The discovery of grounded theory. Chicago: Aldine.

Karahanna, E., Straub, D., \& Chervany, N. (1999). Information technology adoption across time: A crosssectional comparison of pre-adoption and post-adoption beliefs. MIS Quarterly, 23(2), 183-213.

Krumbholz, M., \& Maiden, M. (2001). The implementation of enterprise resource planning packages indifferent organizational and national cultures. Information Systems, 26(3), 185-204.

Lapointe, L., \& \& Rivard, S. (2005). A multilevel model of resistance to information technology implementation. MIS Quarterly, 29(3), 461-491.

Larsen, M., \& Myers, M. (1999). When success turns into failure: A package-driven business process reengineering project in the financial services industry. Journal of Strategic Information Systems, 8, 395 417.

Markus, M.L., \& Tanis, C. (2000). The enterprise systems experience: From adoption to success. In R.W. Zmud (Ed.), Framing the domains of IT management: projecting the future through the past (pp. 173205). Cincinnati, OH: Pinnaflex Educational Resources.

Orlikowski, W. (1992). The duality of technology: Rethinking the concept of technology in organizations. Organization Science, 3(3), 398-427.

Sarker, S. \& Lee, A. (2000). Using a case study to test the role of three key social enablers in ERP implementation. In S. Ang, H. Krcmar, W. Orlikowski, P. Weill, \& J. I. DeGross (Eds.), Proceedings of the 21 st International Conference on Information Systems (pp. 414-425), December 10-13, 2000 Brisbane, Australia. 
Schank, R., \& Abelson, R. (1977). Scripts, plans, goals, and understanding: An inquiry into human knowledge structures. Hillsdale, NJ: Lawrence Erlbaum Associates.

Stein, A., Hawking, P., \& Wyld, D. (2005). B2E SAP portals: Employee self-service case study. In L. Lau, Managing business with SAP: Planning, implementation and evaluation (pp. 90-109). Hershey, PA: IDEA Group.

Steinbach, T., \& Knight L. (2006). The relevance of information systems research: Informing the IS practitioner community; informing ourselves. Proceedings of the 2006 Informing Science and IT Education Joint Conference (pp. 287-298), Salford, UK, June 25-28, 2006. Available at http://proceedings.informingscience.org/InSITE2006/ProcStei190.pdf

Suchman, L. (1987). Plans and situated actions: The problem of human-machine communication. Cambridge, UK: Cambridge University Press.

Taylor, S., \& Todd, P. (1995). Understanding information technology usage: A test of competing models. Information Systems Research, 6(4), 144-176.

Tedlock, B. (2000). Ethnography and ethnographic representation. In N. Denzin \& Y. Lincoln (Eds.), The handbook of qualitative research (pp. 455-486). Thousand Oaks, CA: SAGE.

Travica, B. (2003). Information view of organizations: Contextualizing technology-Technologizing context. Proceedings of AMCIS 2003, August 4-6, 2003, Tampa, FL. (Nominated for the Best Papers Award)

Travica, B. (2004). Organizations as information processes. In A. Jacky, C. Isabelle, \& F. Marc, Process management and information systems. Proceedings of pre-ICIS workshop, Washington D.C., December 12, 2004.

Travica, B. (2005a). Information politics and information culture: A case study. Informing Science Journal, 8, 211-244. Available at http://inform.nu/Articles/Vol8/v8p211-244Travica.pdf

Travica, B. (2005b). Information view of organization, Journal of International Technology and Information Management, 14(3), 1-20.

Travica, B. (forthcoming). Information view of organization. Manuscript in preparation.

Yin, R. (2003). Case study research: Design and methods ( $3^{\text {rd }}$ ed.). Thousand Oaks, CA: SAGE.

\section{Biography}

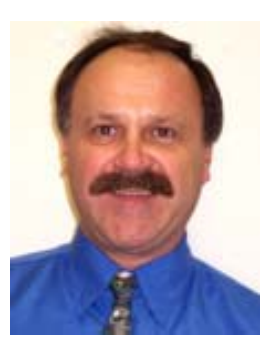

Bob Travica teaches information systems at University of Manitoba, and investigates organizations from the perspective of information and information technology. His current preoccupations are with advancing the information view of organization as a framework for research and teaching. 